\title{
Participatory Futures Imaginations
}

Keywords

Agency, Design, New Media, Participatory Futures, Play.
The contemporary conjuncture of widespread ecological and social crises summons critical thinking about significant cultural changes in digital media design. The selection and classification practices that marked the history of slavery and colonization now rely on all types of nanotechnologies. On behalf of the future, bodies became expanded territory to sovereign intervention, where the role of contemporary powers enable extraction and mining of material, plumbed from the most intimate sphere of the self. This logic requires the state of exception to become the norm, so that the crisis is the digital media's critical difference: they cut through the constant stream of information, differentiating the temporally valuable from the mundane, offering users a taste of real-time responsibility and empowerment. Thereby, this research aims to explore the dynamic transformations of the mediatic environment and their impacts on the fundamental relationships of human beings with the world, the self, and objects. It unfolds concerns around neocolonial assaults on human agency and autonomy that resonate from structuring patterns emerging from the digital infrastructure of neoliberalism and the relationships of human beings with the world. It disputes the imaginaries, representational regimes, and the possibilities of reality perceptions with universal, patriarchal, and extractive representations. This research also seeks alternative forms of media education and political resistance through its collaborative practice, pursuing an attentive and open-ended inquiry into the possibilities latent for designing new communication and information tools within lived material contexts: How might we represent invisible media infrastructures? How to produce knowledge about this space and present it publicly? How can these representations be politically mobilized as ecological and social arguments to establish a public debate? How can artistic sensibilities, aesthetics and the visual field influence what is thought of this frontier space? Finally, how can art, play and research intervene and participate? For this, the project involves participatory methods to create spaces for dialogue between different epistemologies, questioning the forms of ethical and creative reasoning in the planetary media and communication systems; for fostering the technopolitics imagination through playful, participatory futures and transition design frameworks as an ethical praxis of world-making; and for a reconceptualization of autonomy as an expression of radical interdependence between body, spaces, and materiality. The research aims to provide a framework for designing media tools, which incorporates core design principles and guidelines of agency and collective autonomy. It also engages with the transnational conversation on design, a contribution that stems from recent Latin American epistemic and political experiences and struggles, and the wider debate around alternative forms of restoring communal bonds, conquering public discussion spaces, and techno-political resistances through collaborative research practices and participatory methods. 